\title{
Engineering Pedagogy: On the Way to "Education 4.0"
}

\author{
https://doi.org/10.3991/ijep.v10i4.15021 \\ Tatiana Polyakova $\left.{ }^{(}\right)$ \\ Moscow Automobile and Road Construction State Technical University (MADI), Moscow, \\ Russia \\ kafedra101@mail.ru
}

The discussion on engineering education initiated by Editor-in-Chief of the journal Matthias Utesch is now more relevant than ever with fast changes in the society including the violent spread of COVID-19 pandemic. The submissions of Matthias Utesch, Manuel Castro, Elio Sancristobal, Thrasyvoulos Tsiatsos, and David Guralnick are quite enlightening and provide further food for thought regarding engineering education from various points of view.

I am grateful for the invitation to participate in the discussion. I am not an engineer but I have been an active member of the higher technical education system since 1978. During my tenure at the technical university, my scientific interests have evolved from teaching foreign languages at engineering universities to more general issues of engineering education. My self-isolation gave me time to think over the matters brought up by the contributors and I hope that the ideas of a specialist in pedagogy will add one more point of view to the discussion on the problems of engineering education.

Engineering Pedagogy as an educational science identifies and analyzes the social demand and formulates it in terms of its aims; researches and determines the necessary content; selects or works out adequate technologies, methods, and teaching aids fitting the target audience (learners) and learning environment. In other words, Engineering Pedagogy provides answers to well-known basic questions: What for? (Aims), What? (Content), Whom? (Learners), Where? (Environment), With what? (Aids), and How? (Methods). As a result, a recommended pedagogical model is launched into an educational system that is able to secure projected learning outcomes. Throughout its lifetime, the model is sometimes adjusted. Thus, we can define the mission of Engineering Pedagogy as providing scientific foundation for transforming the social demand for professional engineers into satisfying results through the system of engineering education.

The Klagenfurt School of Engineering Pedagogy founded by Professor Adolf Melezinek was established at the time of technological revolution thereby sustaining the prestige of the engineering profession and keeping it in high demand on the technical employment market. The demand for engineers gave a tremendous boost to engineering education but it resulted in the shortage of technical teachers. In some countries the problem was seemingly solved by hiring qualified professional engineers to teach in secondary and higher educational institutions. So, professional peo- 
ple not ready for teaching began their carrier in education. A. Melezinek presented a thorough analysis of the situation in Austria in his presentation at the $1^{\text {st }}$ Symposium of IGIP in 1972 and precisely identified the social demand of that time.

A. Melezinek always insisted that the teacher was the main figure of the educational process. Understanding social demand he defined the aim of technical teachers training as developing Engineering Pedagogy competences. The necessary content for such training was presented in "Ing. Paed. Curriculum" (204 hours). Because A. Melezinek had engineering and pedagogical background, the founder of the Klagenfurt school used the most advanced at that time methods and technical aids of teaching. The program was successfully implemented in the Centre of Engineering Pedagogy and became compulsory for teachers of secondary technical colleges and engineering universities in Austria. Thus, IGIP had managed to provide the answers to those well-known basic questions.

"Ing. Paed. Curriculum" turned out to be a success not only in Austria but also in other European countries because all over the world, as a rule, technical teachers of engineering universities had no pedagogical education. The Centers of Engineering Pedagogy started opening in many countries. The Centers became especially popular in Eastern Europe and Russia, where the system and programs for professional training of teachers had already existed. No doubt, this factor contributed to the dissemination of Engineering Pedagogy in these countries.

The changes in political and economic spheres, as well as the pledge to reform educational systems according to the action lines of the Bologna Declaration required the update of "Ing. Paed. Curriculum". To stay current with the social demand, the new 2005 and 2013 versions of IGIP Prototype Curricula were designed and approved. While engineering education was in this transition period, IGIP with international exchange of practices became even more relevant including Engineering Pedagogy research of educators in many countries.

What are the main objectives of Engineering Pedagogy during the $4^{\text {th }}$ Industrial Revolution which triggers "Industry 4.0"? There is no consensus in understanding whether the revolution has already started or we are just at the threshold of it, everybody agrees that "Industry 4.0 " needs now or will need in the immediate future "Education 4.0 ".

Rapid changes in modern society make the search for the answers to the basic questions of Engineering Pedagogy more challenging than ever before. This search is facing quite a few uncertainties.

Revolutionary changes in techniques and technologies radically influence professional activities of engineers. Professional requirements expand by constantly including new functions. Moreover, every five years add new professions in industry. As a result, we must not only identify and analyze the constantly changing social demand 
but prepare and plan for it. The latter is extremely complicated because, as the great Danish physicist Neils Bohr said, "it is very difficult to predict - especially the future." Needless to point out how many predictions never come true.

Aims (What for?). The problems with identification of the social demand are projected to the process of defining educational aims. We must make regular adjustments to the educational aims to reflect the changes in engineering functionality by introducing corresponding changes in the educational process. Possibly, for the first time Engineering Pedagogy has to also predict such need. The Coronavirus pandemic - a true Black Swan - could not be predicted and now engineers are forced to work remotely, from home, however, quite a few employers turned out to be unprepared for that.

Content (What?). Regular adjustment of engineering education aims require prompt changes in the content of education. Taking into account reduced contact hours, various approaches are suggested for many technical disciplines. I think it is critical to have some "fundamental nucleus" providing engineers with the knowledge to adapt to new professional situations and be ready for a life-long learning. It seems that some educators underestimate the role of knowledge declaring that now it is "available online" which no doubt is true. However, according to some psychologists the inception of new ideas is based on professional/scientific intuition, which is rooted in the encyclopedic knowledge in the field. No less important is the fact that COVID19 pandemic has clearly demonstrated: a professional has to be able to make decisions in extreme situations, like lack of time or without electricity and as a result without any access to the Internet. I doubt that modern engineers with a set of soft skills would survive in the circumstances described by Jules Verne in "The Mysterious Island" without access to Google. Not so easy for Engineering Pedagogy to find an answer to the question "What?", is it?

Learners as the target audience (Whom?). Our students born after 2000 belong to Generation Z, also known as "digital natives". They are different from the previous Generation Y, or "digital immigrants" (born in the 80's and 90's). What is more important, they radically differ from the generation of their teachers as far as their values, psychological and intellectual peculiarities are concerned. Sometimes they are characterized by clip mentality - they are irreplaceable when searching for information but their attention is limited with the so-called "eight-second filters" which are a defense mechanism from information explosion. They have a fantastic operational memory but have problems with long-term memory, cause-effect relationship, analysis, and communication. They aren't bad, they are simply different. That means that now the main participants of the educational process, teachers and learners work in different regimes. To receive an answer to the question "Whom?" we need information from related sciences, for example, cognitive psychology and physiology.

Aids (With what?). Due to developing techniques, information and communication technologies, digitalization, and artificial intellect, teachers have a vast array of state- 
of-the art technical teaching aids at their disposal. Over the years, it has allowed to introduce e-learning, distance education and other forms of progressive teaching. David Guralnick gave very impressive examples in his paper. These achievements have allowed engineering universities to maintain educational process in the period of COVID-19 pandemic. I have little doubt that this unprecedented experience of applying various distant learning aids will have a strong positive effect on the engineering education. My colleague Professor P. Kubrushko has compared this situation with swimming: a crowd of people are standing on the bank of the river. Some are good swimmers, some are beginners, and there are those afraid to even wet their feet. Unexpectedly, all of them find themselves in the middle of the river. They have to swim to survive and so do we. We found ourselves amid a large-scale natural experiment. We must use this unique opportunity to analyze its results and determine which of the various modern instruments have passed the live testing of their efficiency and adaptability to the challenges of the world-wide crisis. This information will provide us with a coherent answer to the question "With what?"

Technologies and methods (How?). The many variables above determine the choice of teaching methods. My colleague, a professor from Portugal, has told me with sadness that we do not know how to teach. But we do and quite effectively but not those who sit in today's classrooms, but the ones who used to sit there decades ago, those who were more like us. And for many years it had worked quite well. Not anymore - the outcome of learning now is below our expectations. The specialists record "educational failure" of new generation learners and are viewing it as a phenomenon worth studying. A bunch of factors influences "educational failure", but the "traditional" methods and technologies of teaching are also responsible for that. Without crucial information from related sciences, we must conduct pedagogical experiments to reveal comparative efficiency or inadequacy of applied methods, as well as the specifics of implementation depending on the teaching environment.

The educational system (Where?). The system of engineering education like any other educational system due to some objective reasons is characterized by certain conservatism and inertance, or lag effect. The conservatism is probably rooted in the necessity to maintain and deliver huge amounts of information gained in technical disciplines over the decades and sometimes over the centuries. This specificity of the engineering education system is both positive and negative. On the positive, it is the aspiration of the system to preserve continuity and integrity. On the negative, it is a slow and lengthy response time to absorbing radically new things.

Therefore, there is a conflict between the fast changes in engineering activities and thus in the profession itself, and certain conservatism of the engineering education system. This contradiction can be observed everywhere. The mission of Engineering Pedagogy has been adversely affected by an array of problems and the shortage of time to solve them. But I have every confidence that it will overcome and succeed on the way from identifying the social demand and its forecasting to implementation of working educational models in the engineering education system. 
As of today, however, the system is not quite stable and has some uncertainty. The biggest challenge facing Engineering Pedagogy on the way to Education 4.0 is to provide coherent answers to its basic questions. Only in this case Engineering Education 4.0 will correspond to Industry 4.0.

Tatiana Polykova

Moscow, April 15, 2020

Tatiana Polyakova - Head of MADI Department of Foreign Languages since 1995, holds the Degree of Candidate of Pedagogical Sciences (Ph.D. equivalent) in methods of foreign language teaching in engineering education, the Degree of Doctor of Pedagogical Sciences in professional education. She is the author, co-author and editor of many national textbooks on English for specific purposes and more than 70 scientific articles on the problems of education.

Tatiana Polyakova has been a member of IGIP since 1998, Chair of the IGIP Working Group "Languages and Humanities in Engineering Education" since 2009, IGIP Executive Committee member since 2010 and IGIP Vice President since 2014. She is the co-author of the book "IGIP: The Past, Present and Future" (2015). She is a member of editorial boards of regularly published journals on Pedagogy. 